\title{
Compliance of nursing care practices with technical recommendations for normal birth
}

\author{
Conformidade das práticas assistenciais de enfermagem com as recomendações técnicas \\ para o parto normal
}

Natasha Faria Barros Guida ${ }^{1}$, Adriana Lenho de Figueiredo Pereira ${ }^{1}$, Gabrielle Parrilha Vieira Lima ${ }^{1}$, Marcele Zveiter $^{1}$, Carla Luzia França Araújo르, Maria Aparecida Vasconcelos Moura ${ }^{2}$

Objective: to describe the compliance of obstetric nursing care practices with the technical recommendations for normal birth. Methods: cross-sectional study of records of normal birth care delivered by nurse-midwifes from two public maternity hospitals. The compliance assessment was based on the World Health Organization recommendations. The two-tailed Z-test was applied. Results: Appropriate compliance was found for all practices assessed at maternity hospital A. At maternity hospital B, the timely clamping of the umbilical cord obtained partial compliance (70.9\%). Prescriptions were found for a null diet, 85.7\% and 59.8\%; oxytocin during labor, $38.7 \%$ and $48.4 \%$; and peri-parturient tocodynamometry, $30.5 \%$ and $47.2 \%$, at maternity hospitals A and $\mathrm{B}$, respectively. Conclusion: the presence of the companion; use of the partogram; non-pharmacological care; intermittent auscultation of fetal heart beat; non-supinal maternal position during child birth; and postpartum application of intramuscular oxytocin obtain appropriate compliance, although inappropriate conducts were observed, such as prescriptions for a null diet, oxytocin and intrapartum tocodynamometry.

Descriptors: Obstetric Nursing; Nursing Care; Humanizing Delivery.

Objetivo: descrever a conformidade das práticas assistenciais de enfermagem obstétrica com as recomendações técnicas para o parto normal. Métodos: estudo transversal dos registros da assistência ao parto normal prestada pelas enfermeiras obstétricas em duas maternidades públicas. A avaliação da conformidade fundamentou-se nas recomendações da Organização Mundial da Saúde. Aplicou-se o teste Z bicaudal. Resultados: todas as práticas avaliadas têm conformidade adequada na maternidade A. Na maternidade B, o clampeamento oportuno do cordão umbilical obteve conformidade parcial $(70,9 \%)$. Verificaram-se prescrições de dieta zero, $85,7 \%$ e 59,8\%; ocitocina no trabalho de parto, $38,7 \%$ e $48,4 \%$; e cardiotocografia periparto, 30,5\% e 47,2\%, nas maternidades A e B respectivamente. Conclusão: a presença do acompanhante; uso do partograma; cuidados não farmacológicos; ausculta intermitente dos batimentos cardiofetais; posição materna não supina no parto; e aplicação de ocitocina intramuscular no pós-parto tem conformidade adequada, contudo, observou-se condutas inapropriadas, como prescrições de dieta zero, ocitocina e cardiotocografia intraparto.

Descritores: Enfermagem Obstétrica; Assistência de Enfermagem; Parto Humanizado.

\footnotetext{
${ }^{1}$ Universidade do Estado do Rio de Janeiro. Rio de Janeiro, RJ, Brazil.

${ }^{2}$ Universidade Federal do Rio de Janeiro. Rio de Janeiro, RJ, Brazil.

Corresponding author: Natasha Faria Barros Guida

Boulevard 28 de Setembro, 157, sala 700. Bairro Vila Isabel. CEP 20-551-050. Rio de Janeiro, RJ, Brazil. E-mail: nashguida@gmail.com
} 


\section{Introduction}

The adoption of good care practices is fundamental in the quality of care provision at maternal and neonatal care services. Care quality assessment includes the analysis of the professional practices' compliance with certain standards of conduct, such as ministerial recommendations, technical standards and scientific evidence ${ }^{(1)}$.

These standards have been described in the recommendations of the ministerial programs and technical standards of the Health Surveillance Agency for maternal and neonatal health, which reference the practices recommended in the World Health Organization document "Care in normal birth care: a practical guide". This guide classifies the care practices in four categories: practices which are useful and should be encouraged; practices which are clearly harmful or ineffective; practices which should be used with caution; and practices which are used inappropriately ${ }^{(2)}$.

Despite these technical recommendations, in a Brazilian research, findings showed that good care practices are used in less than half of the parturient women, and that high proportions of harmful conducts exist. In addition, some procedures are used inappropriately, such as the null diet; oxytocin use; amniotomy, episiotomy and the woman's lithotomic position during childbirth, among others ${ }^{(3)}$.

The relevance of this study is the need for advanced knowledge on the quality of obstetric nursing care, aiming to support the discussion about the importance of appropriate care to improve the maternal and neonatal outcomes, as well as the importance of preventing and controlling the risks associated with improper and obsolete obstetric practices in view of the scientific evidence.

When considering that the nurse-midwives' activities should be based on updated scientific knowledge and on the care standards in force, the following research problem was formulated: To what extent does obstetric nursing care comply with the technical recommendations for normal birth?
To answer this question, the following study was proposed, aiming to describe the compliance of obstetric nursing care practices with the technical recommendations for normal birth.

\section{Methods}

Cross-sectional and documentary study developed at two public maternity hospitals in the city of Rio de Janeiro, Brazil, which have obstetric nursing teams working at the birth center. These professionals deliver care to healthy pregnant women with a regular obstetric risk profile and also serve as tutors for residents. These institutions were named maternity A and maternity B here.

In total, the nursing midwives attended to 789 normal births at maternity A and 683 at maternity B in 2013. The research samples corresponded to 266 normal births these professionals attended to at institution A and 254 at institution B. In the calculation, a $5.0 \%$ sampling error and $95.0 \%$ confidence interval were considered.

The research included the care records of women attended by nurse-midwives during labor and delivery, whose pregnancy was classified as regular risk, single fetus, with flexed cephalic presentation and gestational age between 37 weeks and 41 weeks and six days. Any care without registered participation by the nurse-midwife during labor and delivery and parturient women admitted in the expulsion stage were excluded from the study.

Systematic random sampling was used, based on the final registration number of the woman at each maternity hospital, which ranged from zero to nine, based on a previous numerical list. After the lot sampling process, the maternal histories were requested from the filing sector of each institution and the inclusion and exclusion criteria were applied. The records of this care included in the study were complemented with the care data found in the obstetric nursing registration book.

The research data were the records of care pro- 
vided by nurse-midwives in 2013 , available in the maternal histories and in the specific register for these nurses, in which they make more detailed notes on the care delivered during labor and delivery.

To obtain these data, a two-part structured form was used. The first part contained the parturient women's individual and obstetric data; and the second dichotomous questions on the recommendations and ministerial technical standards for care to normal birth, which were collected between April and August 2015.

The research variables were related to the parturient women's individual and obstetric characteristics (age range, number of prenatal consultations, parity and pregnancy problems) and the data about labor and delivery care (presence of companion; type of diet; walking; prescription of oxytocin; intervention conducts such as amniotomy; Kristeller maneuver and episiotomy; care adopted in each labor period; maternal position to give birth; episiotomy and severe perineal laceration, including $3^{\text {rd }}$ and $4^{\text {th }}$ degree perineal tear).

The assessment of the care practices' compliance was based on the practices classified by the World Health Organization as Category A which are demonstrably useful, should be encouraged during normal birth care and are used in the Brazilian technical standards. The following variables were selected: presence of companion during labor and birth; use of partogram; non-pharmacological care; intermittent fetal heart beat auscultation; maternal non-supine position during birth; timely clamping of umbilical cord and intramuscular application of oxytocin during postpartum.

Compliance was ranked according to how frequently these recommended care practices were executed, with the following value judgment: from 100 till $75.0 \%$ - appropriate compliance; from 74 till 50.0\% - partially appropriate compliance; and inferior to $50.0 \%$ - no compliance ${ }^{(4)}$.

The data were stored and processed in Microsoft Excel 2010, using its statistical and logical func- tions to calculate absolute and relative frequencies and to apply the two-tailed Z test, adopting the critical $\mathrm{Z}$ coefficients $\leq-1.96$ or $\mathrm{Z} \geq 1.96$, with a $95.0 \%$ confidence interval, $a=0.05$ and $p<0.025$. This test was used to verify the significance of the statistical difference between the compliance proportions of the care practices found at maternity hospitals A and B.

The study complied with the formal requirements in Brazilian and international regulatory standards for research involving human beings.

\section{Results}

The parturient women attended by nurse-midwives are predominantly young women, between 15 and 24 years of age, at both maternity hospitals studied. The adolescents, between 15 and 19 years of age, were more frequent at institution $\mathrm{A}(32.7 \%)$ than at institution B (26.4\%). The proportion of women over 34 years of age was $6.4 \%$ at maternity $\mathrm{A}$ and $5.2 \%$ at maternity B.

Women who had seven or more prenatal care consultations were predominant at institutions A (64.7\%) and B (58.7\%), followed by women with four to six consultations. One $(0.4 \%)$ woman did not receive prenatal care at maternity A and two $(0.8 \%)$ at maternity B.

What the parity is concerned, the nulliparous women were more frequent in obstetric nursing care at maternity A (50.8\%), while most of the clients these professionals attended to at institution B (56.3\%) were women with a history of one or more births. The proportion of women with an earlier cesarean section was $4.5 \%$ at maternity A and $5.9 \%$ at maternity B.

Concerning the practices recommended by the World Health Organization, the lack of records on the supply of fluids during labor was found in the study sample at maternity A. These records were found in only six (2.4\%) maternal histories analyzed at maternity B. Consequently, a large number of prescriptions for a null diet were found, with a higher rate at institution A $(85.7 \%)$ when compared to institution B (59.8\%). 
Besides the large proportion of the null diet, practices that are frequently used improperly according to the World Health Organization were also found, such as the prescription of oxytocin during labor and tocodynamometry in the first clinical stage of labor or intrapartum.

Considering these intervention practices, it was identified that $13.9 \%$ of the women at maternity A and $8.3 \%$ at maternity B received an amniotomy. Records of Kristeller's maneuver were observed in $1.9 \%$ of the histories analyzed at institution A and in $2.0 \%$ of the records at institution B. Episiotomy was rare among the women these professionals attended at both research institutions, as described in Table 1.

Table 1 - Practices used in parturient care attended by nurse-midwives at public maternities

\begin{tabular}{lcc}
\hline \multirow{2}{*}{ Practices* } & Maternity A & Maternity B \\
\cline { 2 - 3 } & $\mathbf{n = 2 6 6 ( \% )}$ & $\mathbf{n = 2 5 4 ( \% )}$ \\
\hline Null diet & $228(85.7)$ & $152(59.8)$ \\
Oxytocin during labor & $103(38.7)$ & $123(48.4)$ \\
Intrapartum tocodynamometry & $81(30.5)$ & $120(47.2)$ \\
Episiotomy & $9(3.4)$ & $5(2.0)$ \\
\hline $\begin{array}{l}\text { Source: Patient histories and Normal birth register. }{ }^{*} \text { More than one practice } \\
\text { was used in some parturient women }\end{array}$ &
\end{tabular}

The nurse-midwives' restricted practice of episiotomy resulted in one case of severe perineal tear, as no records of $3^{\text {rd }}$ degree laceration were found in any of the histories analyzed at maternity $A$ and in one $(0.4 \%)$ history of the sample studied at maternity B.

First degree perineal tear occurred in $65.0 \%$ of the women attended at institution A and in $49.2 \%$ at institution B. Second degree tears were more frequent in women who gave normal birth at maternity A $(18.5 \%)$ than at maternity B $(9.0 \%)$.

As regards the World Health Organization's recommendations for care and Brazilian technical standards, the obstetric nursing practices complied in terms of the presence of the companion; use of the partogram; application of non-pharmacological care; intermittent fetal heart beat auscultation; maternal non-supine position during birth and postpartum ap- plication of intramuscular oxytocin at both maternities. It is highlighted that timely umbilical cord clamping in the sample at maternity B obtained partial compliance.

Significant statistical differences were also found in the prevalence rates of these practices recommended by the World Health Organization in the care investigated at both maternity hospitals. Higher rates were found for the presence of the companion, timely umbilical cord clamping and postpartum application of intramuscular oxytocin among the women attended by nurse midwives at maternity A. On the other hand, the use of the partogram and intermittent fetal heart beat auscultation obtained higher frequencies at maternity B. This set of data is displayed in Table 2.

Table 2 - Assessment of compliance of obstetric nursing practices with technical recommendations for normal birth in public maternities

\begin{tabular}{|c|c|c|c|}
\hline \multirow[t]{2}{*}{ Practices } & \multicolumn{2}{|c|}{ 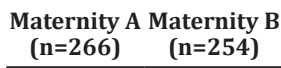 } & \multirow[t]{2}{*}{$\mathbf{p}$} \\
\hline & $\%$ & $\%$ & \\
\hline Presence of companion in labor & $90.6(\mathrm{~A})$ & $84.3(\mathrm{~A})$ & $0.014^{*}$ \\
\hline Use of partogram & $91.0(\mathrm{~A})$ & $96.1(\mathrm{~A})$ & $0.010^{*}$ \\
\hline Non-pharmacological care & $96.6(A)$ & $94.5(\mathrm{~A})$ & 0.119 \\
\hline Intermittent fetal heart beat auscultation & $98.1(\mathrm{~A})$ & $100.0(\mathrm{~A})$ & $0.014^{*}$ \\
\hline Presence of companion at birth & $91.0(\mathrm{~A})$ & $85.0(\mathrm{~A})$ & $0.018^{*}$ \\
\hline Non-supine position at birth & $91.4(\mathrm{~A})$ & $91.3(\mathrm{~A})$ & 0.502 \\
\hline Timely umbilical cord clamping & $82.0(\mathrm{~A})$ & $70.9(\mathrm{P})$ & $0.001^{*}$ \\
\hline $\begin{array}{l}\text { Postpartum application of intramuscular } \\
\text { oxytocin }\end{array}$ & $94.4(\mathrm{~A})$ & $90.6(\mathrm{~A})$ & 0.050 \\
\hline
\end{tabular}

Source: Histories and normal birth register. ${ }^{*}$ Statistically significant difference, $\mathrm{p}<0.025$

Legend: (A) - Appropriate compliance and (P) - Partially appropriate compliance

When specifically considering non-pharmacological care for relaxation, comfort and pain relief of women during labor, the nurse-midwives at maternity B (71.7\%) used deambulation more frequently than at maternity A (57.9\%). These professionals also used the warm shower more at maternity B (65.7\%) than A (51.9\%). Besides this care, records of indications of pelvic movements, massage, use of the bobath ball and birth stool were found at both maternity hospitals. 
Concerning the non-supine maternal positions at birth, vertical positions were predominant in the research samples at maternity A (65.8\%) and B (63.8\%), followed by the lateral position, adopted by $19.5 \%$ of the women attended at institution $\mathrm{A}$ and $18.1 \%$ at institution B.

\section{Discussion}

Initially, it is highlighted that the methodological design of this research entails limitations because it involves specific care realities at two public maternity hospitals; because it presents limitations in the reliability of the actual care provided; and because it was impossible to know whether the interventions registered in the patient histories were practices the nurse midwives had truly indicated.

Concerning the profile of the women the nurse-midwives attended to, the epidemiological data of births in Brazil indicate the predominant maternal profile of young women, between 20 and 24 years of age, who received six or more prenatal consultations ${ }^{(5)}$. Nulliparous pregnant women without associated obstetric risks are these professionals' main clients $^{(6)}$.

The World Health Organization considers the prescription of the null diet, a practice that still prevails at Brazilian maternity hospitals, an improper practice. Prolonged fasting causes maternal and fetal harm due to the ketoacidosis, dehydration, hyponatremia and hypoglycemia. Despite these known effects, it was verified that only $25.2 \%$ of the parturients received food during labor and birth at the Brazilian maternities ${ }^{(3)}$. Therefore, the type of diet offered to the parturients should be adapted to the ministerial technical standards and to international scientific evidence ${ }^{(7)}$.

This revision is also necessary concerning the use of oxytocin, which is still regularly used to accelerate labor and whose combination with early amniotomy is called active management of labor. Evidence demonstrates that routine early amniotomy offers no maternal and neonatal benefits, whether associated with oxytocin or not. Therefore, its routine practice is not indicated for women whose labor progresses normally ${ }^{(8)}$.

The World Health Organization does not recommend active management to prevent prolonged labor either and does not recommend intravenous oxytocin administration until a change in the progression of labor is confirmed ${ }^{(2)}$. In healthy parturients, routine oxytocin infusion is not recommended and can cause complications for mother and infant if not appropriately controlled ${ }^{(7)}$.

The prevalence rates of oxytocin use in the research samples follow the same trend found in research about birth in Brazil, which identified its use in $38.2 \%$ of the regular-risk parturients ${ }^{(4)}$. At a hospital service where the nurse-midwives work, it was verified that oxytocin was used in $43.8 \%$ of the nulliparous women in labor and that not all preset criteria for its indication were totally complied with ${ }^{(9)}$.

Therefore, despite the risks associated with oxytocin use, its use still prevails in hospitals, despite the good health condition of the women giving birth $^{(3-10)}$, even in hospitals where obstetric nurses and midwives are available. This high prevalence can be related with the hospital care culture.

Another conduct associated with the hospital environment is continuous electronic monitoring of the fetal cardiac heartbeat or tocodynamometry. Besides inhibiting free maternal walking, this type of monitoring presents false-positive results of fetal problems, provoking an increased risk of unnecessary interventions, mainly cesarean sections. Despite this risk, the frequencies of this monitoring were high at the maternity hospitals studied and, therefore, this conduct is line with the intermittent fetal auscultation recommendations for healthy parturients ${ }^{(11)}$.

Despite these inadequacies, obstetric nursing care presents advances in the compliance with technical standards, such as a frequency rate of episiotomy at about $2.0 \%$. This result contrasts with the realities at Brazilian maternity hospitals, where it is practiced in $53.5 \%$ of the parturients ${ }^{(3)}$. Episiotomy is a common 
surgical procedure around the world with variations by country, ranging from $9.6 \%$ in Sweden to $91.0 \%$ no Nepal ${ }^{(12)}$. The World Health Organization argues that its practice should range around $10.0 \%{ }^{(2)}$.

The vertical positions in labor are associated with lower episiotomy rates and increased second-degree perineal tears ${ }^{(7)}$, while instrumental vaginal birth, the infant's weight and shoulder dystocia are associated with severe perineal traumas, third and fourth-degree tears ${ }^{(13)}$. Instrument use and working in cases of labor dystocia go beyond Brazilian nurse-midwives' professional scope and, therefore, cases of severe perineal tear are not or rarely expected in these professionals' practice, as verified here.

What the companion's presence is concerned, both maternity hospitals presented compliance rates superior to $84.0 \%$. In a study at a public maternity hospital that is a reference institution for regular risk, similar rates were demonstrated (83.0\%) for the companion's presence during birth ${ }^{(14)}$.

The use of the partogram was not universal in the research samples, with frequency rates of $91.0 \%$ and $96.1 \%$. The partogram is the graphical representation of labor, which permits monitoring its evolution and indicating appropriate conducts. Therefore, it is expected to be used for all women in labor with a view to guaranteeing the quality of care. A study at three maternity hospitals found the presence of the partogram in $98.5 \%$ of the histories of pregnant women at regular risk ${ }^{(10)}$. At two maternity hospitals in the North, this graphical tool was absent in only $2.2 \%{ }^{(15)}$.

Despite these needs for advances, compliance was found concerning the non-pharmacological care the obstetric nurses apply, with frequency rates superior to $94.0 \%$. This percentage is higher than what is observed at Brazilian maternity hospitals, where only $28.0 \%$ of the women of regular obstetric risk benefitted from this care $^{(3)}$.

Pain relief during labor is a widely disseminated theme, with a wide range of care to promote the parturient woman's comfort and relaxation, such as walking, massages, shower, rhythmical breathing, relaxation techniques, among others ${ }^{(9-16)}$. The World Health Organization recommends this care to favor the physiological evolution of labor and pain relief. In the international context, this care is recommended to promote a positive labor and birth experience ${ }^{(16)}$.

Among the care that needs to be encouraged in normal birth, the timely clamping of the umbilical cord at maternity B (70.9\%) was the only care that does not comply with the recommendations, according to the compliance criterion adopted here. It is highlighted that, after birth, timely clamping is the physiological mode of treating the umbilical cord and is executed between one and three minutes after bir$\operatorname{th}^{(17)}$. Therefore, the obstetric nurses at maternity B should adapt their care practice to comply with these technical standards.

To prevent postpartum hemorrhage, the World Health Organization recommends to application of intramuscular oxytocin after the detachment of the infant's shoulders. This care is fundamental to prevent this event, which is the main cause of maternal mortality in low-income countries and the primary cause in about a quarter of all maternal deaths in the world ${ }^{(18)}$.

The results found here demonstrate that the nurse-midwives use the practices in compliance with the technical recommendations, suggesting that increasing the number of these professionals at Brazilian public maternity hospitals can contribute to the adaptation of obstetric care for the sake of improved maternal and neonatal health, and also indicate that the institutional routines need to be adjusted to truly achieve better care outcomes.

\section{Conclusion}

The presence of the companion during labor and birth; use of the partogram; non-pharmacological care; intermittent fetal heart beat auscultation; non-supine maternal position at birth and postpartum application of intramuscular oxytocin are appropriate 
practices the nurse-midwives use and which comply with the World Health Organization recommendations and ministerial technical standards for normal birth at the two maternity hospitals investigated. Nevertheless, conducts were observed that are inappropriate for healthy parturient women, such as prescriptions of a null diet, intrapartum oxytocin and tocodynamometry.

\section{Collaborations}

Guida NFB contributed to the project conception, analysis and interpretation of the data. Lima GPV, Zveiter M and Araújo CLF contributed to the writing of the article and relevant critical review of the intellectual content. Pereira ALF and Moura MAV contributed to the final approval of the version for publication.

\section{References}

1. Agência Nacional de Vigilância Sanitária (BR). Serviços de atenção materna e neonatal: segurança e qualidade. Brasília: Agência Nacional de Vigilância Sanitária; 2014.

2. Organização Mundial de Saúde. Assistência ao parto normal: um guia prático. Genebra: Organização Mundial de Saúde; 1996.

3. Leal MC, Pereira APE, Domingues RMSM, Theme Filha MM, Dias MAB, Pereira MN, et al. Obstetric interventions during labor and childbirth in Brazilian low-risk women. Cad Saúde Pública. 2014; 30(supl1):17-32. doi: http://dx.doi. org/10.1590/0102-311X00151513

4. Barreto ASB, Mendes MFM, Thuler LCS. Avaliação de uma estratégia para ampliar a adesão ao rastreamento do câncer de mama no Nordeste brasileiro. Rev Bras Ginecol Obstet. 2012; 34(2):86-91. doi: http://dx.doi.org/10.1590/ S0100-72032012000200008

5. Viellas EF, Domingues RMSM, Dias MAB, Gama SGN, Theme Filha MM, Costa JV. Prenatal care in Brazil. Cad Saúde Pública. 2014; 30(supl 1):85100. doi: http://dx.doi.org/10.1590/0102$311 \times 00126013$
6. Vieira MJO, Santos AAP, Silva JMO, Sanches METL. Obstetrical nursing care based on good practices: from admission to delivery. Rev Eletr Enf [Internet]. 2016 [cited 2017 Jun 13]; 18:e1165. Available from: https://dx.doi.org/10.5216/ree. v18.36714

7. Singata M, Tranmer J, Gyte GML. Restricting oral fluid and food intake during labour. Cochrane Database Syst Rev. 2013; (8):CD003930. doi: http://dx.doi.org/10.1002/14651858. CD003930.pub2

8. Bugg GJ, Siddiqui F, Thornton JG. Oxytocin versus no treatment or delayed treatment for slow progress in the first stage of spontaneous labour. Cochrane Database Syst Rev. 2013; (6):CD007123. doi:http://dx.doi.org/10.1002/14651858. CD007123.pub2

9. Ekelin M, Svensson J, Evehammar S, Kvist LJ. Sense and sensibility: Swedish midwives ambiguity to the use of synthetic oxytocin for labour augmentation. Midwifery. 2015; 31(3):36-42. doi: http://dx.doi.org/10.1016/j.midw.2014.12.006

10. Oliveira FAM, Leal GCG, Wolff LDG, Gonçalves LS. The use of Bologna Score to assess normal labor care in maternities. Rev Gaúcha Enferm. 2015; 36(spe):177-84. doi: http://dx.doi. org/10.1590/1983-1447.2015.esp.56940

11. Alfirevic Z, Devane D, Gyte GML. Continuous cardiotocography (CTG) as a form of electronic fetal monitoring (EFM) for fetal assessment during labour. Cochrane Database Syst Rev. 2013; (5):CD006066. doi: http://dx.doi. org/10.1002/14651858.CD006066

12. Schantz C, Sim KL, Ly EM, Barennes H, Sudaroth S, Goyet S. Reasons for routine episiotomy: A mixedmethods study in a large maternity hospital in Phnom Penh, Cambodia. Reprod Health Matters. 2015; 23(45):68-77. doi: http://dx.doi. org/10.1016/j.rhm.2015.06.012

13. Gurol-Urganci I, Cromwell DA, Edozien LC, Mahmood TA al. Third- and fourth-degree perineal tears among primiparous women in England between 2000 and 2012: time trends and risk factors. BJOG. 2013; 120(12):1516-25. doi: http://dx.doi.org/10.1111/1471-0528.12363 
14. Apolinário D, Rabelo M, Wolff LDG, Souza SRRK, Leal GCG. Practices in delivery and birth care from mothers' perspective. Rev Rene. 2016; 17(1):208. doi: http://dx.doi.org/10.15253/21756783.2016000100004

15. Carvalho IS, Brito RS. Using the Bologna Score to assess normal delivery healthcare. Rev Esc Enferm USP. 2016; 50(5):741-48. doi: http://dx.doi. org/10.1590/s0080-623420160000600005

16. National Institute for Health and Care Excellence. Intrapartum care for healthy women and babies. London (ENG): National Institute for Health and Care Excellence [Internet]. 2014 [cited 2015 Oct. 20]. Available from: https://www.nice.org.uk/ guidance/cg190\#
17. McAdams RM. Time to implement delayed cord clamping. Obstet Gynecol. 2014; 123(3):549-52. doi: http://dx.doi.org/10.1097/ AOG.0000000000000122

18. World Health Organization. Recommendations for the prevention and treatment of postpartum hemorrhage: evidence base [Internet]. 2012 [cited 2015 Oct. 20]. Available from: http://www.who. int/reproductivehealth/publications/maternal_ perinatal_health/9789241548502/en/ 